\title{
SODOBNA RABA PRIPOVEDNEGA IZROČILA \\ V OBČINI ROGAŠKA SLATINA IN OKOLICI
}

KATARINA ŠRIMPF VENDRAMIN

Rabo kulturne dedišcine lahko opazujemo skoraj v vseh segmentih javnega dogajanja. Uporablja se za namene kulturnih in turističnih prireditev, kot vir, iz katerega crpajo zamisli različni ustvarjalci. Različne oblike dedišcine labko s svojo pojavnostjo predstavljajo tudi simbolno identiteto lokalne skupnosti. Članek obravnava različne oblike pojavnosti dedišcine, vezane predvsem na pripovedno izročilo, ter simbolno predstavljanje lokalne identitete in pripadnostiv občini Rogaška Slatina in okolici.

Ključne besede: kulturna dedišcina, pripovedno izročilo, folklorizem, lokalne identitete
Cultural heritage is used in nearly all segments of public life. It is used for cultural and tourism events as a source from which various artists and performers draw their ideas. Through the various forms it appears in, heritage can also represent a symbolic identity of the local community. This article examines the various forms of heritage that are primarily connected with narrative tradition, and the symbolic representation of local identity and affiliation in the Municipality of Rogaška Slatina and the surrounding area. Keywords: cultural heritage, narrative tradition, folklorism, local identities

\section{O FOLKLORIZMU IN RABAH DEDIŠČINE}

Raba dediščine za mnogotere namene, od političnih in ideoloških do takšnih za namene kulturnih in turističnih prireditev ali kot polje, iz katerega črpajo ideje različni ustvarjalci, bodisi folklorne skupine, gledališki ustvarjalci ali drugi umetniki, je bila v strokovni javnosti obravnavana že mnogokrat. Že v prvi polovici 20. stoletja so folkloristi začeli zaznavati ekonomske komodifikacije in politične manipulacije z elementi nesnovne kulturne dediščine (Bendix 2009: 176). Te pojavne oblike so raziskovalci opredelili kot folklorizem, nekaj, kar ni prava folklora, ampak »drugotna folklora ali folklora iz druge roke«. V tem pomenu je termin leta $1962 \mathrm{v}$ etnologijo vpeljal nemški etnolog Hans Moser v članku „Vom Folklorismus in unserer Zeit" (1962: 180; gl. tudi Bendix 2009: 176; Poljak Istenič 2013: 142; Stanonik, Terseglav in Slavec Gradišnik 2004: 131). V prvih poskusih opredelitve je zaznal tri pojavne oblike folklorizma: izvedba tradicionalnih in funkcionalno določenih elementov ljudske kulture v lokalni skupnosti ali družbeni plasti; razigrane posnetke ljudskih motivov v drugi družbeni plasti; namenski izum in ustvarjanje elementov, ki so podobni ljudskim, zunaj katere koli tradicije (Moser 1962: 190).

Uporabo termina folklorizem sicer raziskovalci postavljajo že v 30. leta 20. stoletja, vendar so ga pisci takrat uporabljali v različnih pomenih. V slovenskem prostoru naj bi ga prvi leta 1935 uporabil kritik in esejist Ivo Brnčič za uporabo slovstvene folklore v književnosti. V folkloristiki pa je že pred Moserjevo uvedbo termina v evropski etnologiji o »vse večji popularizaciji, komercializaciji in posledično izkrivljanju ljudskega gradiva« kritično 
pisal ameriški folklorist Richard M. Dorson (Bendix 2009: 190). Z nizom člankov po letu 1959 je za takšne pojave uporabljal termin fakelore ali lažna folklora (Dorson 1969; Stanonik 2006: 264, Bendix 2009: 189-194).

Slovenski folkloristi in etnologi so po 2. svetovni vojni folklorizem prepoznavali predvsem na turističnih prireditvah v povezavi s šegami. Kljub temu, da so obravnave folklorizma v etnoloških delih pogoste, so do nedavnega ostajale bolj na deskriptivni ravni; raziskovalci so naštevali različne prireditve, jih časovno opredelili, opisovali sestavine in nosilce, ter se do njih predvsem kritično opredelili (Poljak Istenič 2013: 144). Ob obravnavi pojavnosti dediščine, opredeljenih kot folklorizem, so se raziskovalci, ne samo v slovenskem prostoru, ampak tudi po svetu, ukvarjali predvsem z vprašanjem avtentičnosti pri uprizarjanju. To temelji na ideji »da je obstajala ali da obstaja izvirna oblika neke kulturne vsebine, glede na katero so uprizorjene izvedbe bolj ali manj pristne ali prave«, je ugotavljal Miha Kozorog ob analizi domače etnološke literature (Kozorog 2014: 27-29). Slovenski etnologi so bili do pojavov folklorizma sprva predvsem kritični, a neizostreni (več o tem Slavec Gradišnik 2000: 305, 376, 427-430): «najvišje so ocenili tiste primere folklorizma, ki so bili najbolj podobni domnevnemu izvirniku oz. je bila rekonstrukcija fenomena najbolj strokovna» (Poljak Istenič 2013: 146). Tudi na polju folkloristike se vrednotenju pojavov folklorizma niso izognili. Tako je Marija Stanonik slovstveni folklorizem definirala kot »rezultat priličenja" ali predelave slovstvene folklore z namenom, da streže množičnemu uporabniku. Folklorizem je opredelila kot trivialno, komercialno različico slovstvene folklore (Stanonik 2006: 265, 271). Nekateri raziskovalci pa so pojavne oblike, opredeljene kot folklorizem, preprosto ignorirali in se še naprej posvečali obravnavi "prave« folklore (Bendix 2009: 179; Slavec Gradišnik 2010: 138-139).

Istočasno z vrednotenjsko obravnavo folklorizma so obstajali tudi drugačni pogledi raziskovalcev. Že kmalu po Moserjevi uvedbi termina folklorizem so se pojavili kritiki, ki so opozarjali na preveč posplošeno rabo termina in prizmo avtentičnosti (za več glej npr. Bendix 2009: 179-185; Poljak Istenič 2013: 142). Tako je, na primer, nemški etnolog Hermann Bausinger kritično odgovoril na razprave o tem s postavitvijo osmih tez o folklorizmu, ter opozoril, da so to le pojavi, ki so izraz novih načinov življenja in pogleda na svet, ter da zato folklorizma ni mogoče ločiti od izvirne folklore (Bausinger 1966: 61-72). Podobno je premišljala tudi folkloristka Linda Dégh, ki ni ločevala folklore od folklorizma tako kot npr. Dorson, saj je folkloro razumela z vidika nenehnega spreminjanja, tudi pod vplivom novih tehnologij in množičnih medijev. Folkloro je opredelila kot produkt zgodovinskih procesov, interakcije pisnega in ustnega izročila, profesionalnosti in neprofesionalnosti, formalnega in neformalnega, improvizacije in ustvarjalnosti. Folklora je zanjo skupek različnih pojavnih oblik, ki so družbeno pomembne in odmevne, temeljijo na tradiciji in so prilagojene potrebam ljudi (Dégh 1994: 1-3). Pri nas je že na samem začetku razprav o folklorizmu Marija Makarovič opozorila na to, da je treba na nove pojavne oblike dediščine gledati kot na izraz danega časa in ne kot rekonstrukcijo preteklosti (Makarovič 1968: 4). Danes se folklorizem še vedno najpogosteje definira kot družbeno-kulturni pojav: kaže 
se lahko v obliki rekonstrukcije največkrat že pozabljenih oblik ljudske kulture ali pa kot njihovo vključevanje $\mathrm{v}$ turizem, kulturo in politiko. Je torej življenje folklore zunaj (domnevno) izvirnega okolja, kar prinese tudi spremembe njene funkcije, a ne le te, temveč tudi ravni delovanja, ko se, na primer, njen lokalni socialni in simbolni pomen preneseta na pokrajinsko/narodno raven (Poljak Istenič 2008: 69).

Folklorizem služi različnim namenom. Najpogosteje so to turistično-komercialni ali politično-propagandni nameni, istočasno pa lahko folklorizem zadovoljuje tudi nekatere druge potrebe ljudi, kot na primer: iskanje osvežitve v eksotiki in preprostosti, željo po spoznavanju drugih krajev in narodov, nostalgijo po izgubljeni tradiciji, potrebam, da se tradicija ohranja vsaj v nekaterih oblikah, željo po sprostitvi v prostem času in tudi zbujanje nacionalnega in lokalpatriotskega ponosa (Bošković-Stulli 1971: 175). Tako lahko folklorizem s svojimi pojavnimi oblikami ohranja pomen lokalne in etnične identitete, vzdržujejo pa ga "patriotska, politična, stanovska, turistična, komercialna in kulturna funkcija» (Stanonik, Terseglav in Slavec Gradišnik 2004: 132).

Danes termin folklorizem večina raziskovalcev uporablja brez vrednotenjske konotacije (npr. Hafstein 2018; Poljak Istenič 2013; o folklorizaciji Habinc 2012). Folklorizem je razumljen preprosto kot adaptacija, transformacija dediščine, folklore v zelo različnih oblikah, od avdiovizualnih (glasbena, plesna, likovna in slovstvena folklora) pa vse do pojavov ljudskega življenja in materialne kulture $\mathrm{v} » k u l t u r n i$ industriji« ali kulturnih programih, ki so povezani s političnimi dejavnostmi (Poljak Istenič 2013: 143).

Kljub vmesnemu zatonu uporabe izraza folklorizem ga nekateri raziskovalci ponovno vpeljuje in sicer $\mathrm{v}$ razprave o pojavih, povezanih z ohranjanjem in varovanjem, še posebej nesnovne kulturne dediščine pod pokroviteljstvom Unesca, in sicer v kontekstu procesa folklorizacije. Islandski etnolog Valdimar Hafstein ugotavlja, da prakse varovanja in predstavitve nesnovne kulturne dediščine rutinsko vključujejo prevajanje dediščine v različne žanre predstavitev dediščine, npr. Unescove sezname, tekmovanja, državne sezname kulturne dediščine, izbore najboljših prikazov, izvedb, ter festivalov. Posebej slednji spodbujajo kondenzacijo, prilagodljivost in spektakelske učinke, ki privabljajo turiste; hkrati pa folklorizacija spodbuja premislek ljudi o lastnih praksah in tako dediščini daje drugo življenje v obliki predstav o sebi (Hafstein 2018: 143). Folklorizacijo pa se lahko razume tudi kot adaptacijo dediščine, njeno rekontekstualizacijo ali transformacijo z namenom ustvariti nekaj novega ali z namenom da le ta ostane javna, prisotna. Folklorizacija oz. varovanje kulturne dediščine je razumljeno kot proces modernizacije (Kirschenblatt-Gimblett 2004: 61; Habinc 2012: 192-193; Hafstein 2018: 129-131).

Za folklorizem in folklorizacijo so $\mathrm{v}$ znanstveni rabi tudi drugačni pogledi in poimenovanja, na primer raba dediščine, dediščinske prakse, dediščinjenje, tudi javna folklora itn. (glej npr. Bogataj 1992; Kirschenblatt-Gimblett 2004: 61; Hudales in Visočnik 2005; Jezernik 2005; Baron in Spitzer 2010; Slavec Gradišnik 2010: 139; Fakin Bajec 2011; Bajuk Senčar 2013). Uporaba terminologije je torej odvisna od pogleda raziskovalca in deloma tudi od njegovega kulturnega in akademskega okolja. 


\section{SODOBNE PRIPOVEDNE PRAKSE V OBČINI ROGAŠKA SLATINA IN OKOLICI}

V nadaljevanju bom predstavila in analizirala dva pojava na območju Rogaške Slatine; v njiju se elementi slovstvene folklore uporabljajo za različne namene. Pozorna bom na funkcije in vidike, ki jih lahko imajo oblike folklorizma v lokalnem okolju.

Sodobna uporaba pripovednega izročila oz. slovstvene folklore gre v več smeri. V Sloveniji je v zadnjih letih mogoče zaznati vse več organiziranih pravljičnih uric, pripovedovalskih večerov, festivalov in delavnic pripovedovanja. Pripovedovalski festival-Pravljice danes je med temi dogodki po starosti in odmevnosti najbolj poznana prireditev. Od leta 1998 postaja vsako leto vedno bolj znan in dobro obiskan kulturni dogodek, katerega glavni namen je predstavljanje slovenskega in tujega pripovednega izročila. $\mathrm{Na}$ festivalu in podobnih dogodkih so se uveljavile tudi pripovedovalke, kot so Anja Štefan, Špela Frlic, Ana Duša, Ljoba Jenče, Irena Cerar in druge, ki tudi sicer vodijo različne pripovedovalske dogodke in so med glavnimi nosilci t. i. slovenske pripovedovalske scene. Tako so nosilke in usmerjevalke novih pripovedovalskih dogodkov, avtoritete, ki »kanonizirajo" (ritualno) prakso (Fikfak 2003: 18). Vedno več je tudi dogodkov, kjer izročilo predstavljajo in podajajo v knjižnicah. Tudi v Knjižnici Rogaška Slatina v zadnjih letih organizirajo pravljične urice za otroke, vendar ob teh priložnosti v prvi vrsti ne berejo pravljic slovenskega izročila. V sosednji občinski knjižnici pa že nekaj let prirejajo Pravljične večere za odrasle; ob teh priložnostih pa pripovedovalke interpretirajo zgodbe iz slovenskega pripovednega izročila, povezanega $z$ izbrano tematiko, na primer s pravljicami o škratih, vilah, zmajih, pravljicami iz Rezije in Prekmurja.

Izkoriščanje različnih oblik dediščine za tržne namene ni nova praksa. Dediščina se uporablja predvsem v turizmu kot strategija za izboljšanje ekonomskega položaja posameznikov ali za lokalni razvoj. Dediščinski turizem pogosto temelji na historičnih posebnostih ali znamenitostih ter na motivaciji in percepciji turistov, ki jih takšne vsebine zanimajo (Poljak Istenič 2013: 129, 138). Za privabitev turistov uporablja predvsem slovstveno, glasbeno in plesno izročilo, izdelke domače in umetnostne obrti, hrano, etnično zgodovino, šege in navade, vse pa je predstavljeno kot posebna zanimivost turističnega kraja (Chhabra 2003: 703).

Eden izmed tržnih prijemov v turizmu so različne tematske poti, ki so v zadnjih letih postale precej priljubljen turistični produkt. Takšnih poti je po Sloveniji kar nekaj. Pri nastanku nekaterih s(m)o sodelovali tudi folkloristi, etnologi in drugi strokovnjaki s področja preučevanja kulturne dediščine. Najnovejša pravljična pot, ki poteka tudi v bližini Rogaške Slatine, je nastala pri projektu Interreg Slovenija - Hrvaška »Živa coprnija» $(2017-2019)^{1}$ in vodi po Slovenski Bistrici in njeni okolici. Dopolnili k poti sta slikanica,

1 Za več informacij glej spletno stran projekta (Spletni vir 1) in članek Ivančič Kutin in Kropej Telban 2018. 


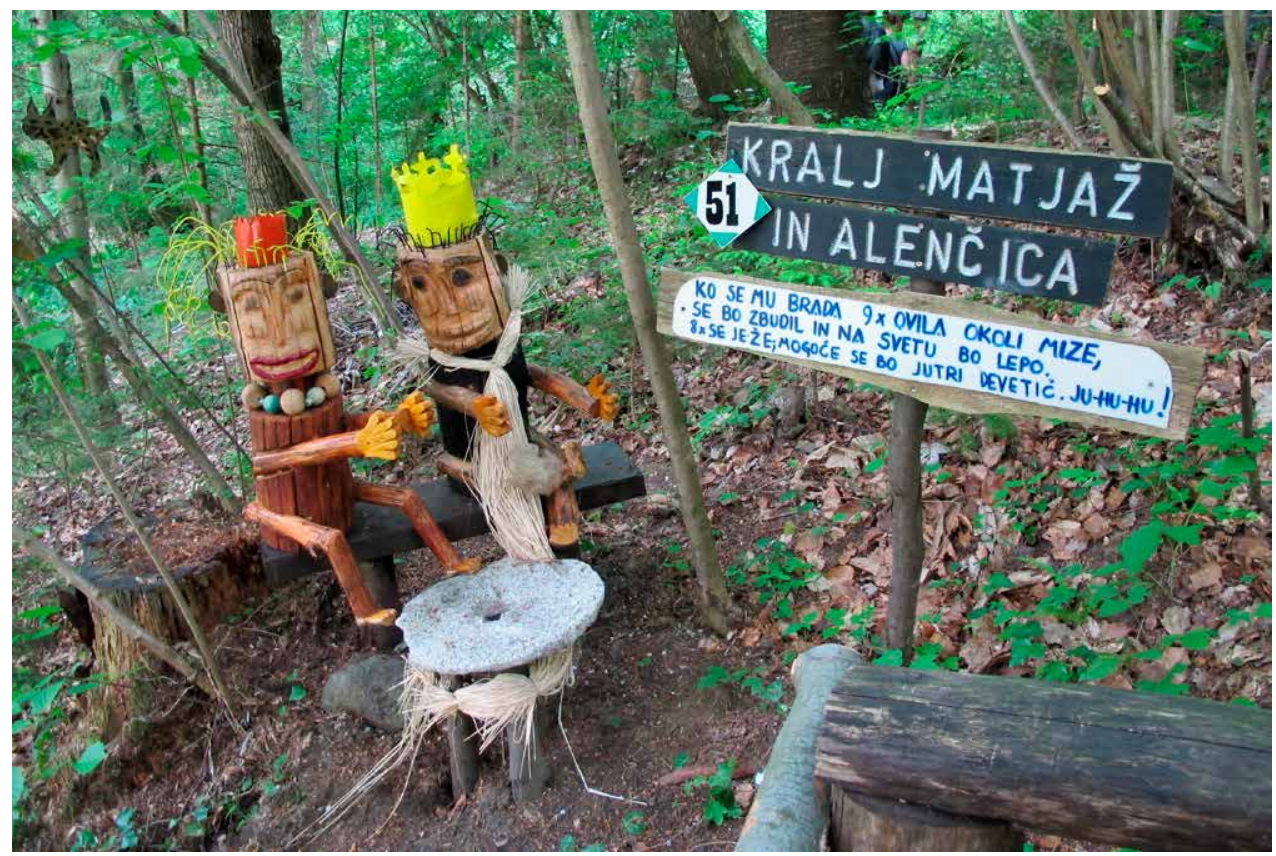

Eden izmed predstavljenih pravljičnih junakov pri Koči pri čarovnici v Olimju. Foto: Katarina Šrimpf Vendramin, 2015.

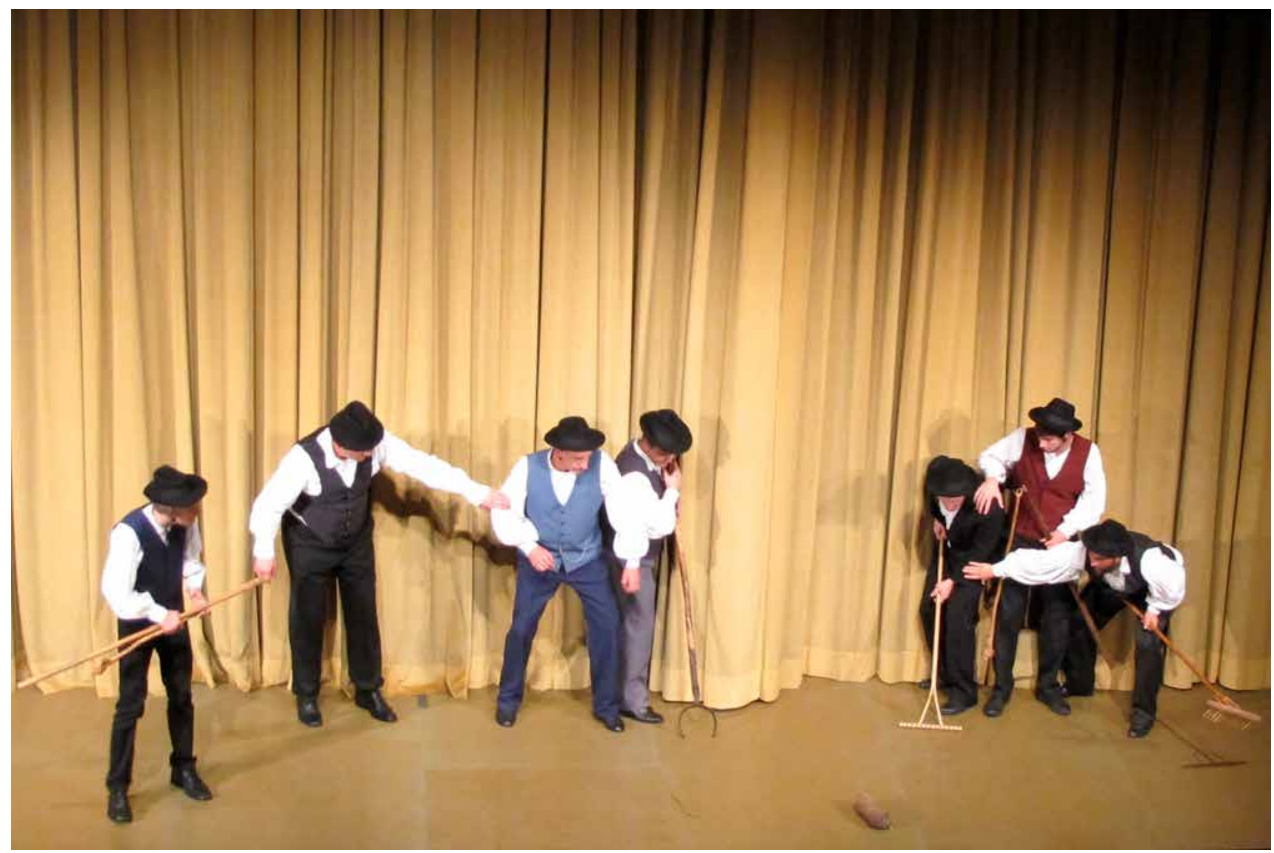

Prizor iz predstave Izgubljeni zaklad - uprizoritev šaljive zgodbe Kako so Lemberžani kašnato klobaso ustrelili. Foto: Katarina Šrimpf Vendramin, 2014. 
ki je uporabna tudi kot vodnik, in pa spletna aplikacija, t. i. digitalni vodnik, s katerim obiskovalec spremlja zgodbe, povezane s kraji na pravljični poti. Že leta 2007 je izšla knjižica Po poteh zgodb. Knjižica je nekakšen vodnik, v njej pa so predstavljeni predlogi za poti po različnih krajih na Kozjanskem, prek katerih je predstavljeno pripovedno izročilo tega območja (Mencej 2007).

Nekoliko bolj kot lokalno izročilo so za snovalce dodatne turistične ponudbe očitno zanimive pravljice bratov Grimm in druge bolj poznane slovenske in tuje avtorske pravljice. Eden izmed takšnih ponudnikov v okolici Rogaške Slatine je že od leta 1992 park Koča pri čarovnici v Olimju v Občini Podčetrtek. Začetnik tega parka v gozdičku, kjer se obiskovalec sprehaja ob številnih postavitvah lutk in drugih predmetov, ki predstavljajo like in prizore iz popularnega slovenskega in svetovnega pripovednega izročila, je bil učitelj Jože Brilej. Čeprav danes v parku ne prevladujejo prizori iz lokalnega pripovedovanja, je prav to spodbudilo nastanek Koče pri čarovnici (Ivančič Kutin in Marjanić 2015: 155).

Za vse sodobne rabe folklore velja, »da iz zaloge tradicijske kulture izbira le nekatere elemente, ki iz določenih vzrokov postajajo atraktivni zaradi svoje artistične forme ali emocionalne vsebine« (Poljak Istenič 2008: 68). Ti elementi so pogosto predelani in uporabljeni v obliki, ki zadovolji estetske, praktične in druge potrebe (prav tam). Ljudske pravljice in povedke so navdih tudi za različne gledališke predstave. V Lutkovnem gledališču Ljubljana imajo tako na sporedu predstavo Štirje muzikanti, za katero je avtor Matija Solce iskal navdih v znani živalski pravljici, ki jo je Niko Kuret povezal tudi z trgom Lembergom. ${ }^{2} \mathrm{~V}$ predstavo je avtor spretno vključil različne folklorne elemente, kot so uganke, pregovori, glasba in pesmi.

Ne samo v Ljubljani, marveč tudi v krajih v Občini Rogaška Slatina, je pripovedno izročilo našlo pot na oder. Boč odstira tančico skrivnosti je bila prva predstava, ki se je oprla nanj. Leta 1992 jo je uprizoril Martin Druškovič, učitelj, kulturnik in zbiralec lokalnega izročila iz Kostrivnice pri Rogaški Slatini. V letu 2014 je skupaj s hčerjo Jasno Druškovič pripravil še muzikal Izgubljeni zaklad. Zgodbe, ki se sicer pripovedujejo in so del ustnega izročila, sta ustvarjalca predstave vzela za osnovo, jo nadgradila in iz tega ustvarila glasbeno, pevsko in scensko predstavo. Vanjo sta vključila zgodbe, ki so sicer, glede na opravljeno raziskavo, ${ }^{3}$ dokaj poznane in so že bile objavljene v različnih publikacijah. V predstavo so bile tako vključene tri različice zgodbe o zmaju, ki prebiva v notranjosti Boča, zgodba o Pegazu, o razbojnici Špeli, belih ženah ali Faricah, ki naj bi prebivale na Boču, etiološka povedka o Formilah, zgodba o toplem potoku v Studenicah. Uprizorili pa so tudi, kako so Lemberžani kašnato klobaso ustrelili in kako so se jim noge pomešale. Nekatere zgodbe o Lemberžanih so povezali v pesemsko obliko, v kateri so omenjali izvolitev župana s pomočjo

2 Gre za pravljico Kako so živali hotele za godce v Lemberg (Kuret 1954: 19). Lemberg je sicer manjši kraj v Občini Šmarje pri Jelšah. Poznane so številne šaljive zgodbe na račun neumnosti tamkajšnjih prebivacev.

3 Raziskava o pripovednem izročilu v zgornjem Obsotelju je bila opravljena v sklopu doktorskega študija v letih 2010-2015. Za več gl. Šrimpf Vendramin 2015. 
žgancev, motiv lovljenja meseca, magistrat brez oken, oranje njive s purani, vlečenje bika v zvonik, povečanje cerkve z gnojenjem, kopanje v lanu in lovljenje svinje po žitu. V predstavo so vključili tudi nekaj priredb ljudskih pesmi, na primer »Ko je Bog ta grešni svet ustvaril«, in pa lokalno ljudsko pesem, ki velja skoraj za nekakšno himno vasi Kostrivnica, z naslovom »Konjski furež« (Druškovič in Druškovič 2014). V letu 2018 je ista gledališka skupina uprizorila še muzikal Razbojnik Guzej, pri katerem so za osnovo vzeli sicer literarizirane obdelave pripovedi o Francu Guzeju in ne zgodb iz lokalnega izročila, o človeku, ki je imel mnogo oznak - »razbojnik, morilec, predrznež, tolovaj, hudodelec, prekocuh, rokomavh, rokovnjač, vagabund, nesrečnež, zoprnik oblastem, maščevalec, pustolovec, nebodigatreba, upornik, ropar, zlikovec ... Pa vendar človek, željan ljubezni, razumevanja, topline ...« (Druškovič 2019: 2).

Raziskovalci so ugotavljali, da pogosto raziskovalci s svojim delom (ne)hote podelimo smisel, pomembnost in obliko nekemu dogodku, ki temelji na tradiciji (Fikfak 2003: 18). Prav posegi različnih strokovnjakov za dediščino vplivajo na to, kaj ljudje počnejo. spremenijo odnos in razumevanje ljudi do lastne kulture in sebe (Kirschenblatt-Gimblett 2004: 58). In ravno ta pretok folklorističnega znanja, perspektiv in v širšo javnost, kjer se oblikujeta razumevanje in odnos javnosti do družbenih praks, je mogoče razumeti kot folklorizacijo (Hafstein 2018: 143).

Tudi sama sem sodelovala v procesih folklorizacije dediščine. Kot domačinka, strokovnjakinja sem namreč pomagala pri ustvarjanju koreografije za otroško folklorno skupino Spominčice na II. osnovni šoli v Rogaški Slatini. Za obogatitev odrske postavitve, katere glavna tema je bila grad, sem tako predlagala vključitev pripovedi o hudobnem graščaku iz Janine, ki jo je objavil Janko Orožen v knjigi Gradovi in graščine v narodnem izročilu (Orožen 1936: 185-186). Glede na temo se mi je zgodba zdela primerna tudi za predstavitev pripovednega izročila lokalnega okolja učencem prve in druge triade, ki plešejo v folklorni skupini. Skupina se je tako leta 2012 na območnem srečanju otroških folklornih skupin, ki ga organizira Javni sklad za kulturne dejavnosti, predstavila s koreografijo z naslovom Hudobni graščk.

Sodelovanje z lokalno učiteljico Mojco Pažon pa je spodbudilo tudi Projekt ohranjanja ljudskih pripovedi. V letu 2016 so se na podružnični šoli Kostrivnica vse leto ukvarjali s lokalnim pripovednim izročilom. Celoletno dogajanje in ukvarjanje $s$ to tematiko so na koncu povezali v predstavo, muzikal, v kateri so uprizorili šest pripovedi. Oblikovali so jo otroci skupaj s starši in jo na predstavitvenem dnevu uprizorili pod naslovom Rajžamo po starem novim časom naproti (Pažon 2016).

Nekateri raziskovalci so skušali ugotoviti, zakaj je sodobna uporaba nekaterih folklornih žanrov tako priljubljena. Finska folkloristka Merja Leppälahti je analizirala bajna bitja iz pripovednega izročila, ki se pojavljajo v fantazijski literaturi in ugotovila, da bajna bitja iz folklore v tem tipu literature delujejo kot simboli: odnos do narave, zdrav slog življenja, morda celo tisto, kar je nekoliko zastarelo, ampak dobro. $S$ folklornimi bitji avtor obuja takšne teme, ne da bi jih poudarjal verbalno. Ugotovila je, da je folklora tolikokrat uporabljena kot 
vir navdiha, ker jo ljudje poznajo, lahko jo je lahko uporabiti in je ni težko razumeti. V teh novih oblikah "avtentičnost", ne samo v literarnih predelavah, ampak tudi v predstavah, ni več pomembna, niti ni več pomembno, da so elementi folklore spoznani kot taki. Po njenem mnenju je to tretje življenje folklore (Leppälahti 2011: 175).

Tehnološki napredek in pomen (spletnih) medijev sta $v$ zadnjih desetletjih korenito spremenila družbo in življenje ljudi. Mediji so postali orodje, s katerim je mogoče doseči različne namene: od politične in tržne propagande do prenosa in popularizacije pravljic, mitov in legend. Tako že nekaj desetletij etnologi, antropologi in folkloristi preučujejo pojavnost folklore tudi v medijih in na svetovnem spletu. Tako je zanimiv pojav tudi Facebookova stran Rogaška Slatina nekoč, ki jo od leta 2013 ureja lokalni zbiratelj in navdušenec za zgodovino Robert Reich. Na strani objavljajo fotografije in video posnetke iz bolj ali manj oddaljene preteklosti kraja kakor tudi različne zgodbe iz življenja domačinov. Prav objave zgodb, ki so jih za spletno stran prispevali sledilci, domačini, so spodbudile nastanek knjige Šnicl ni za tebe (Reich 2019), v kateri je avtor zapisal spomine in zgodbe (objavljene tudi na Facebookovi strani) iz novejše zgodovine Rogaške Slatine in njenih prebivalcev oz., bolj slikovito ubesedeno, "kolektivno zavest slatinskega lokalpatriotizma«, ${ }^{4}$ kakor je zapisano v uvodniku (Poljanec 2019: 5).

\section{O PEGAZU IN LOKALNI IDENTIFIKACIJI}

Kot sodobne pojave folklorizma lahko razumemo tudi uporabo različnih oblik dediščine, ki predstavljajo simbolno identiteto lokalne skupnosti ali širše. Ali, kot je povzela Saša Poljak Istenič: "folklorizem je torej del folklornega procesa, zavestno prepoznanje, prilagajanje, uporaba in ponavljanje ljudskih tradicij kot simbola identitete lokalne ali regionalne skupnosti, etnične skupine ali naroda" (Poljak Istenič 2008: 74). Folklorizmu soroden koncept je koncept izumljenih, iznajdenih tradicij (v angl. invented tradition), ki izhaja iz politične antropologije. V poglavjih knjige The Invention of Tradition (Hobsbawm in Ranger 2000) so različni avtorji pokazali, da so tradicije, ki se zdijo stare ali se za take razglašajo, po izviru pogosto razmeroma mlade in včasih celo iznajdene, izmišljene. $S$ pomočjo obeh konceptov je mogoče analizirati tudi simbolno predstavljanje lokalne identitete in pripadnosti, ki se izraža v različnih oblikah, tako ustvarjanja simbolov kot tudi z različnimi kulturnimi dejavnostmi in oblikami (nekatere so že bile opisane), tudi v občini Rogaška Slatina.

4 Knjiga v nakladi 1000 izvodov je bila razprodana v treh mesecih. Kupci so bili predvsem domačini oz. ljudje, ki so v določenem obdobju življenja živeli ali bili povezani z Rogaško Slatino. Bralce je, sodeč po komentarjih na Facebookovi strani, zelo pritegnila. Nekateri so celo objavljali fotografije, kje vse so jo brali (na morju, na potovanjih, doma itn.). Glede na odzive je knjiga postala obvezno branje za zavednega domačina. 


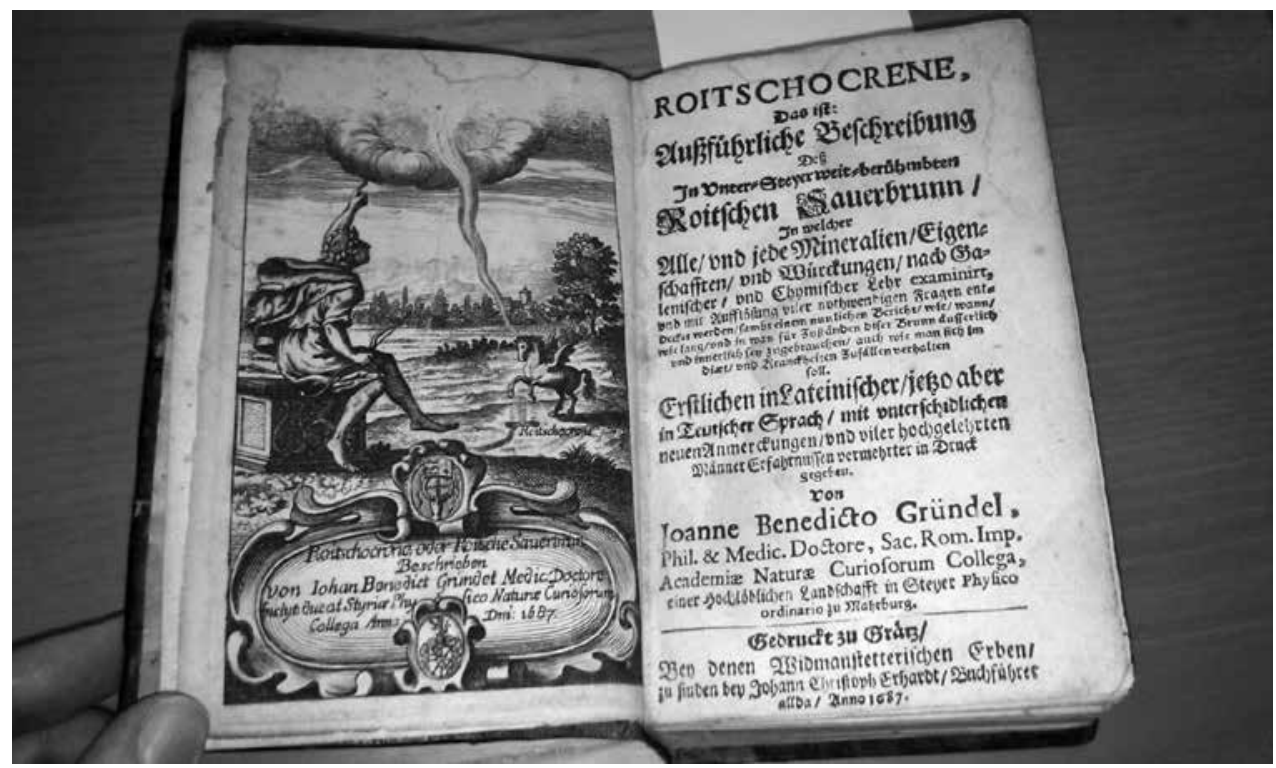

Fotografija strani knjige Johana Benedicta Gründla z naslovom Roitschocrene, kjer je upodobljena legenda o Pegazu in njegovem odkritju mineralne vode v Rogaški Slatini. Foto: Katarina Šrimpf, 2014.

Med vsemi predstavljenimi oblikami folklorizma ali izumljenih tradicij pa je najzanimivejša podoba Pegaza, ki je simbol Občine Rogaška Slatine. Ker se je kot simbol pojavil razmeroma pred kratkim, lahko sledimo procesom ustvarjanja in identifikacije $s$ tem simbolom ter $s$ tem tudi poudarjanju in nenehni graditvi lokalne pripadnosti, ki jo omogoča podoba mitološkega krilatega konja.

Občina Rogaška Slatina je za podlago za nastanek novega občinskega simbola leta 2002 izbrala legendo o Pegazu. Legendo $s$ krajem povezujeta zapis in upodobitev v nemški izdaji knjige Roitschocrene Johana Benedicta Gründla iz leta 1687 (Gründl 1687). Na spletni strani občine Rogaška Slatina je zapisana tako:

Zgodba govori, da je bog Apolon Pegaza pozval, naj na upodobljenem mestu (bližina Rogatca in cerkve sv. Križa, ki je na pričujoči grafiki upodobljena v ozadju) udari s kopitom in tako odpre Roitschocrene, rogaški vrelec, podobno kot je po grški mitologiji odprl lasten vrelec Gippocrene (hippos - konj). (Spletni vir 2)

Kot atribut kraja je mitološkega konja Pegaza arhitektka Andreja Straže Lotrič postavila tudi v grb in zastavo občine. Čeprav so na spletni strani občine Rogaška Slatina zapisali, da se Pegaz redko pojavlja v grboslovju, pa naj bi bila njegova uporaba kljub temu heraldično pravilna. $\mathrm{V}$ utemeljitvi zasnove grba in $\mathrm{v}$ drugih opisih in omembah zaznamo tudi stalno poudarjanje povezanosti grba $\mathrm{z}$ legendo. Pomembno vlogo pri izbiri motiva za grb je očitno imelo tudi iskanje enkratnosti in $s$ tem prepoznavnosti. To razkriva zapis na 


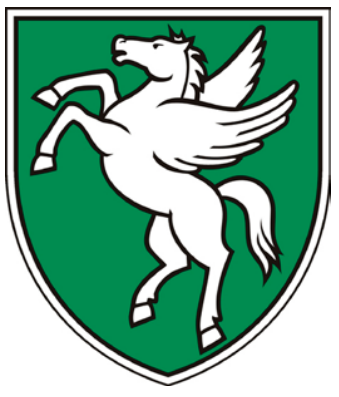

Grb občine Rogaška Slatina (Spletni vir 2)

spletni strani občine Rogaška Slatina: "postave Pegaza ne srečujemo v grbih skupnosti, kar zagotavlja grbu unikatnost in s tem lahko prepoznavnost občine Rogaška Slatina v družbi lokalnih skupnosti Zahodne in Srednje Evrope« (Spletni vir 2). Pegaz je s postavitvijo v občinski grb in zastavo, kakor so zapisali, postal »simbolni stvarnik rogaške mineralne vode, bistvenega elementa za razvoj tako kraja kot občine Rogaška Slatina« (prav tam).

Čeprav je Hobsbawmov koncept izumljenih tradicij tudi kritiziran, nam je v tem primeru lahko v oporo pri analizi graditve lokalne pripadnosti s pomočjo Pegaza, ki jo je v Občini Rogaška Slatina spodbujala oblast in ne prebivalci. Čeprav kritiki opozarjajo, da »izumljene tradicije» niso nujno popolnoma na novo iznajdene, marveč lahko dejansko izvirajo v tradiciji (npr. Portis-Winner 2005: 45-47), pa glede na dosegljive podatke v primeru Pegaza v Rogaški Slatini to ne drži. Zgodba namreč v pripovednem izročilu območja ni bila poznana vse do omenjene občinske odločitve, naj Pegaz postane simbol kraja.

Hobsbawm je izumljene tradicije razvrstil v tri skupine: prve ustvarjajo in simbolizirajo družbeno povezanost ali pripadnost neki skupini; druge vzpostavljajo ali legitimirajo ustanove, status ali razmerja do avtoritet; glavni namen tretjih je socializacija, utrditev vere, vrednostnega sistema in vedenjskih konvencij (Hobsbawm in Ranger 2000: 9). Oblikovanje grba in zastave ter podoba Pegaza kot glavnega motiva, ki naj bo občinski simbol, sodita v prvo in drugo skupino: namen je povezati skupnost, v tem primeru občane Rogaške Slatine, in simbolno pokazati in potrditi dolgo zgodovino kraja.

Izumljene tradicije se kažejo v formalizaciji in ritualizaciji, zgledujejo se po preteklosti in zahtevajo ponavljanjev (Hobsbawm in Ranger 2000: 1-2); to se lahko vidi tudi v tem primeru. Motiv in zgodba, $s$ katerima je bil zasnovan grb, namigujeta na povezavo $z$ antiko in s tem poudarjata starost kraja in zdravilne slatine. Vsaka vnovična objava bakroreza in zgodbe iz knjige Roitschocrene pa še dodatno legitimira »resničnost « domnevnega izročila in upravičenost do posebnega statusa kraja, ki s tem navidez dokazuje večtisočletno zgodovino. Zgodba o nastanku slatinskih vrelcev se pojavlja skoraj v vseh opisih in predstavitvah kraja, kajti vsakokratno ponavljanje zgodbe je potrebno, da simbol kraja oz. zgodba o njegovem nastanku živi naprej.

Čeprav se zgodba o Pegazu večinoma povezuje z Rogaško Slatino kot krajem in čeprav je simbol celotne občine, si jo lastijo tudi v Kostrivnici, manjšem kraju v občini:

Rogaška si lasti sicer, dobro je, mi smo to pač zdej nekak [...] Kojn naj bi potoval, Pegas, veste, kojn naj bi potoval in ko je pripotoval, naj bi pripotoval tudi v Kostrivnico in kjer je udaro, je pač voda prišla ven na dan, ne. To si mi to zgodbo tudi lastimo in tak naprej. In mi smo tudi to pripovedko zelo živo prikazali pred dosti letami. ${ }^{5}$

5 Povedala Marija Čakš, upokojenka. Posneto v Kostrivnici, 22. 12. 2010. 


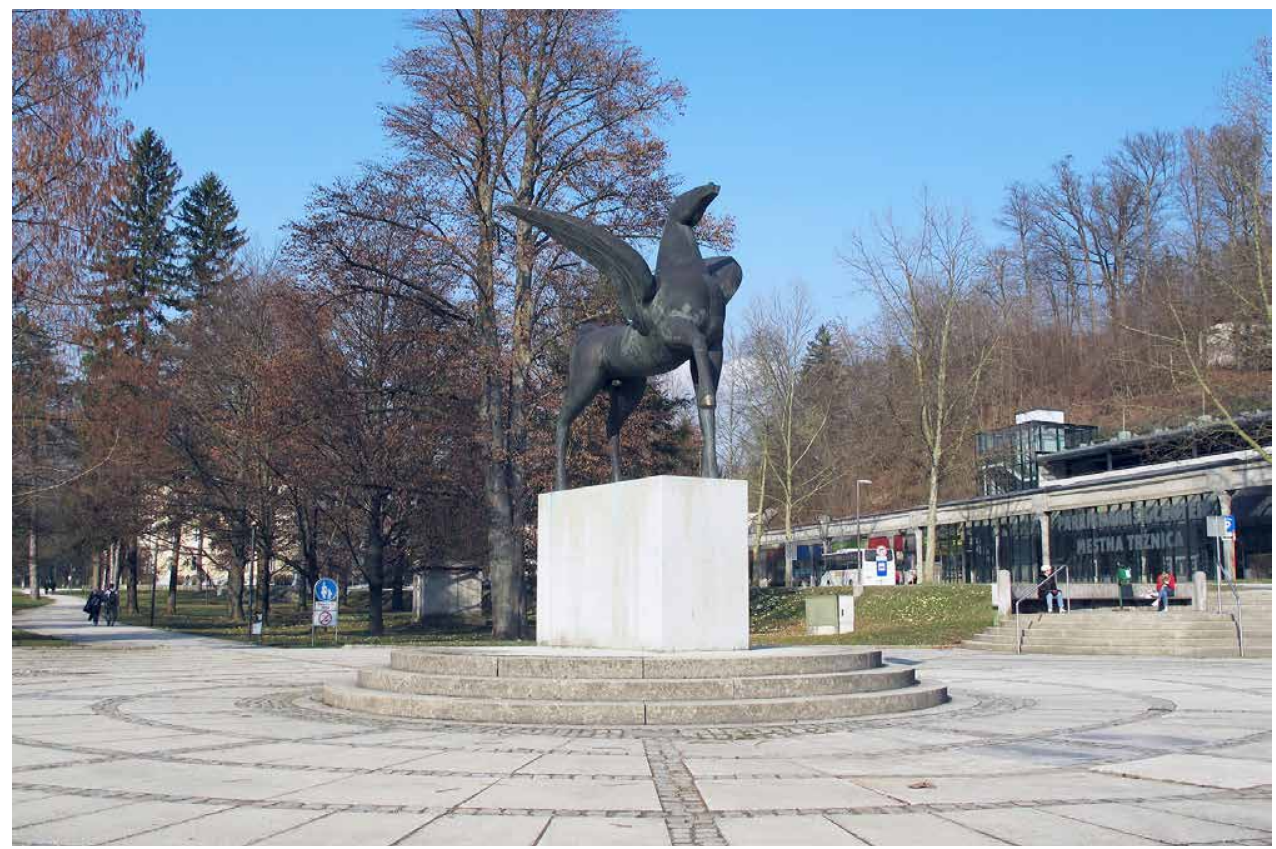

Kip Pegaza v središču Rogaške Slatine. Foto: Katarina Šrimpf Vendramin, 2015.

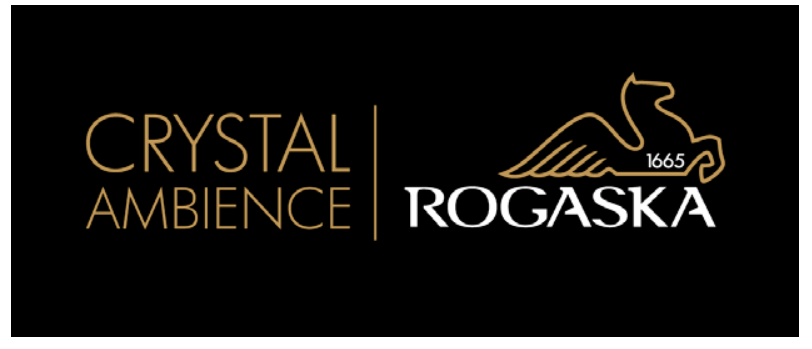

Logotip podjetja Steklarna Rogaška (Spletni vir 3).

Simbol občine v podobi kipa Pegaza je bil leta 2008 postavljen tudi v samo središče kraja. Petmetrskemu bronastemu kipu, ki ga je izdelal akademski slikar in kipar Vasilij Ćetković Vasko, so namenili osrednje mesto na prostoru, ki so ga poimenovali Pegazova ploščad. S kipom in z njim povezano legendo je lokalna oblast še dodatno poudarila pomembnost tega lika kot glavnega atributa občine.

Odkar je občina za lokalni simbol postavila mitološkega krilatega konja, so ga lokalni prebivalci že povsem ponotranjili in sprejeli. Tako je $\mathrm{v}$ občini dom za ostarele $\mathrm{z}$ imenom Pegazov dom, Moto klub Pegaz Rogaška Slatina, ženska vokalna zasedba z imenom Pegazove muze, glasbena skupina Pegaz, picerija in restavracija Pegaz in Pub Pegaz. V logotip so podobo Pegaza vključili na I. Osnovni šoli Rogaška Slatina in tudi v Steklarni Rogaška, pa še kaj bi se našlo. To kaže, da je Pegaz postal »emocionalno in simbolično nabita podoba« (Hobsbawm in Ranger 2000: 11), ki predstavlja pripadnost kraju. 
Nove tradicije ali izumljene tradicije so razmeroma poljubne, kar zadeva vrednote, pravice in dolžnosti, pa vendar promovirajo patriotizem, lojalnost, odgovornost, šolski duh. Krepi jih njihovo poudarjanje, obnavljanje in ponavljanje ob ritualnih priložnostih (tako kakor npr. petje himne, dviganje zastave ipd.). Za njihovo ohranjanje so bistveni emocionalno in simbolično nabiti znaki in simboli, kot so zastava, grb in himna. S temi atributi tudi neodvisna država razglasi svojo identiteto in suverenost in kot takšni zahtevajo spoštovanje in lojalnost, v njih pa se zrcalijo tudi celotno ozadje, misli in kultura naroda (Hobsbawm in Ranger 2000: 10-11). To se je s spremembo grba posrečilo tudi lokalnim oblastem $\mathrm{v}$ občini Rogaška Slatina. S podobo Pegaza so dobili simbol, s katerim se prebivalci občine čustveno identificirajo, občina pa z grbom in zastavo kaže svojo samostojnost in identiteto, zgrajeno na zgodovinskosti kraja.

\section{O PARZIVALU IN NJEGOVI UMEŠČENOSTI NA BOČ}

Primer folklorizacije, ki na novo gradi povezavo Boča in okoliških krajev, so zgodbe in dogodki navezani na srednjeveški ep o Parzivalu. Parzival je pesnitev Wolframa von Eschenbacha, ki ga je ta ustvaril v začetku 13. stoletja in velja za enega največjih spomenikov srednjeveške književnosti. V pesnitvi je opisana zgodba Parzivala, ki se od mladeniča povzpne do viteza Arturjeve okrogle mize.

Na svojih viteških potovanjih Parzival nekega dne prijezdi do Gralovega gradu, kjer je priča skrivnostnemu ritualu. Kose naslednje jutro zbudi, je grad prazen. Misleč, da so Gralovi vitezi odšli v boj, odjezdi za njimi, da bi jim pomagal, vendar pa se njihovi sledovi v gozdu kmalu izgubijo. S tem se začenja Parzivalovo dolgotrajno iskanje, da bi znova našel pot do Gralovega gradu. (Ciglenečki in Ciglenečki 2018: 177).

Kot sta ugotavljala Jan in Slavko Ciglenečki se lokacija Gralovega gradu povezuje z Bočem od konca 19. stoletja. Prva znana oseba, za katero je mogoče sklepati, da je Wolframov ep in omenjeni Gralov grad povezoval z Bočem, naj bi bil Karl (Johann) Julius Schmidt, učitelj telovadbe na učiteljski šoli, ki je bil po rodu Nemec iz Köslina v Prusiji. Schmidt je namreč v feljtonu "Krainische Studien”, objavljenem v časniku Laibacher Wochenblatt leta 1893, omenil to povezavo, na katero so se očitno oprli tudi vsi poznejši avtorji (Ciglenečki in Ciglenečki 2018: 183-185).

Popularizacija zgodbe o Parzivalu in Boču ter nanjo vezani kulturni dogodki postavljajo goro Boč in okoliške kraje v mitološko pokrajino. Po ugotovitvah terenske raziskave zgodbo pozna le peščica med seboj povezanih ljudi. Tudi sama sem jo slišala le od ene sogovornice:

Je legenda, da je v Boču srebrno jezero, v njem pa plava čoln, na čolnu je angel in na glavi mu stoji ptič. In potem zgodba o Parcifalu in njegovem sinu, se pa nanaša 
na Parcifala pa njegovega sina, veř, zgodbo? On je bil šibek deček in Parcifalov meč je meč moči in meč preobrazbe in poslanstva in kdo ga je ven potegno je dobil moč in se je preobrazo v poslanstvo in vsi so se mu norca delali, eh, kaj boš ti, ne. In prav on je potegno ta meč ven. ${ }^{6}$

Da je to zgodba ozkega kroga ljudi, ki jim je skupno zanimanje za duhovnost, dajejo slutiti tudi spletne objave. Avtorica večine člankov, ${ }^{7}$ v katerih se omenja povezava Parsifala in Boča, je sociologinja Jožica Amadea Demšar, ki med drugim vodi delavnice za osebni razvoj in duhovnost. Zdi se, da je prav ona moje sogovornike seznanila s to povezavo. Danes med svojimi storitvami ponuja tudi izkustveno delavnico »Boč in njegova (po)moč«: udeleženci na delavnici potujejo "skozi svete prostore Boča«, kot so »starodavni keltski obredni krog, skalo Svečenikov, jamo Belojačo, jamo Balunjačo, Arturjevo skalo ter dolino toplega potoka s krajem Studenice (Spletni vir 4). Komentar ene od sogovornic v raziskavi je bil: Duhovni turizem je zdaj čas, da prihaja. Zato te legende zdaj oživljajo. Vešs, ko greš na Boč, jih doživirs. ${ }^{8}$ To na neki način tudi nakazuje namerno »obujanje« nekaterih zgodb ali, bolje rečeno, iznajdevanje novih, ki se jih povezuje predvsem s prostorom Boča.

$\mathrm{V}$ času, ko je bil Maribor evropska prestolnica kulture, sem zasledila konferenco, posvečeno tej pesnitvi, leta 2014 pa še projekt z imenom Terra Parzival (Spletni vir 5). Idejni vodja projekta je violinist in kulturni ambasador Slovenije Miha Pogačnik. Gre za šestletni projekt, ki naj bi s trženjem zgodbe o Parzivalu pomagal pri razvoju turizma v Podravski regiji. Namenjen naj bi bil:

lokalnemu inovativnemu povezovanju prebivalstva na ožjem geografskem področju Terre Parzival oz. t. i. Parzivalove dežele, zamejene z zgodovinskimi in legendarnimi mejniki legende o vitezu Parzivalu: Ptuj, Rogatec, Rogaška, Donačka gora, Celje, Žička kartuzija, Boč, Ptuj z gradovoma Borl in Štatenberg v središču. (Spletni vir 6)

Na spletni strani Terra Parzival je dostopen spored štiridnevnega popotovanja in delavnic po deželi Parzivala.

\section{TURIZEM IN RABA PRIPOVEDNEGA IZROČILA}

Razmeroma veliko je oblik folklorizma, ki služijo turističnim namenom, vendar pa ugotavljam, da je za turistične namene na obravnavanem območju raba izročila razmeroma skromna.

6 Povedala D. L. (1960), Rogaška Slatina, 19. 10. 2011. Zgodba je podobna zgodbi o kralju Arturju, ki je prav tako potegnil meč iz kamna.

7 Na različnih spletnih straneh je mogoče najti precej podobna besedila; avtorica nekaterih je Jožica Demšar sama ali pa gre za pogovore z njo (gl. Jeranko 2009; Demšar 2017; Spletni vir 4).

8 Povedala Darinka Lorger (1960), Rogaška Slatina, 19. 10. 2011. 
Kljub temu da ima predvsem Rogaška Slatina bogato zgodovino in je evropsko poznan turistični kraj, zgodb iz izročila, vezanega na zdravilišče, ne izkoriščajo. Tako gosti večinoma ne izvedo, da je, na primer, na otvoritvi drugega Zdraviliškega doma leta 1846 igral Franz Liszt ali da je v bližini Kostrivnice imela vilo Berta von Suttner, ki je kot prva ženska leta 1905 prejela Nobelovo nagrado za mir (Širca 2014). Po izročilu, ki kroži med ljudmi, ki se zanimajo za zgodovino kraja, ji je vilo kupil sam Alfred Nobel. V Rogaški Slatini naj bi bil tudi začetek slovite tovarne Kraš, saj je v Rogaški Slatini družina Bizjak (Bizjak keksi) imela svoj prvi obrat. Pozneje so se preselili v Zagreb in s svojimi izdelki postali del tovarne Kraš.

Turizem v sosednjih občinah, z izjemo Podčetrtka, ni posebej razvit. Nihče pa za oglaševanje turistične ponudbe ne uporablja pripovednega izročila - tudi v občini Rogaška Slatina ne. Muzej na prostem Rogatec je na tem območju edina ustanova, ki promovira dediščinski turizem, saj je njihov glavni tržni produkt prav dediščina, vendar tržijo le obrtno (pletarstvo, tkalstvo, kovaštvo, kamnoseštvo, po novem tudi steklarstvo) ter pripravo kruha (žulike), plesno in glasbeno izročilo. Pripovednega izročila v muzeju ne predstavljajo, čeprav bi z njim lahko obogatili svoj ponudbo.

Čeprav ima pripovedno izročilo potencial za uporabo v tržne in promocijske namene, pa kaže, da te možnosti ne vidijo v nobeni od treh občin, zato tudi ni izkoriščeno ali pa v zelo majhnem obsegu. So pa ta potencial očitno odkrili drugi, saj projekt Terra Parzival izkorišča prav ta segment. Tudi avtorica knjige Pravljične poti Slovenije je spoznala potencial dediščinskega turizma in tudi pripovednega izročila tega območja. V knjigo je namreč vključila dve poti, ki temeljita na pripovednem izročilu, in sicer zgodbo o okamnelem zmaju, ki ima glavo pri Rogatcu, ter zgodbi o vilah in Špelci v jami Balunjači (Cerar Drašler 2004: 24-30).

Bernhard Tschofen je (sicer na primeru zaščite lokalne hrane) ugotavljal, da je znanje o kulturni dediščini pomemben segment pri zaščiti lokalnih produktov, predvsem zaradi čustvene vrednosti, ki ponuja možnosti za identifikacijo (Tschofen 2012: 35). Podobne pojave je mogoče zaznati tudi pri sodobni rabi folklornih pojavov v smislu folklorizma. Dediščina ima tudi emocionalo plast, pogosto sicer v romantičnem odnosu do nje, ki narekuje, da jo je treba zaščiti, ker izginja. Organizirajo se tematske poti, pripovedovalski večeri in festivali, da bi določene vsebine prišle spet med ljudi. Kadar pa je pri teh dogodkih, kakor tudi pri drugih rabah dediščine, zelo poudarjeno lokalno izročilo, pa pojavi folklorizma omogočajo lokalne identifikacije. Vse oblike, v katerih se pojavlja izročilo, nakazujejo, da se raziskovalci moramo ukvarjati tudi s temi pojavi in iskati vzroke, zakaj so tako mikavni za množico ustvarjalcev na različnih področjih. Tschofen je v zvezi s tem zapisal, da bomo raziskovalci morali razviti

večjo občutljivost za različne načine "ustvarjanja kulture", ki se posebej kažejo v zvezi s kulturno dedišcino: za prakse, ki so hkrati podvržene hitrim spremembam in pomagajo ustvarjati kontinuiteto, in za interpretacije, ki so hkrati samoumevne in izrazito kontradiktorne. To zahteva, da veliko pozornost namenimo načinu, kako se 


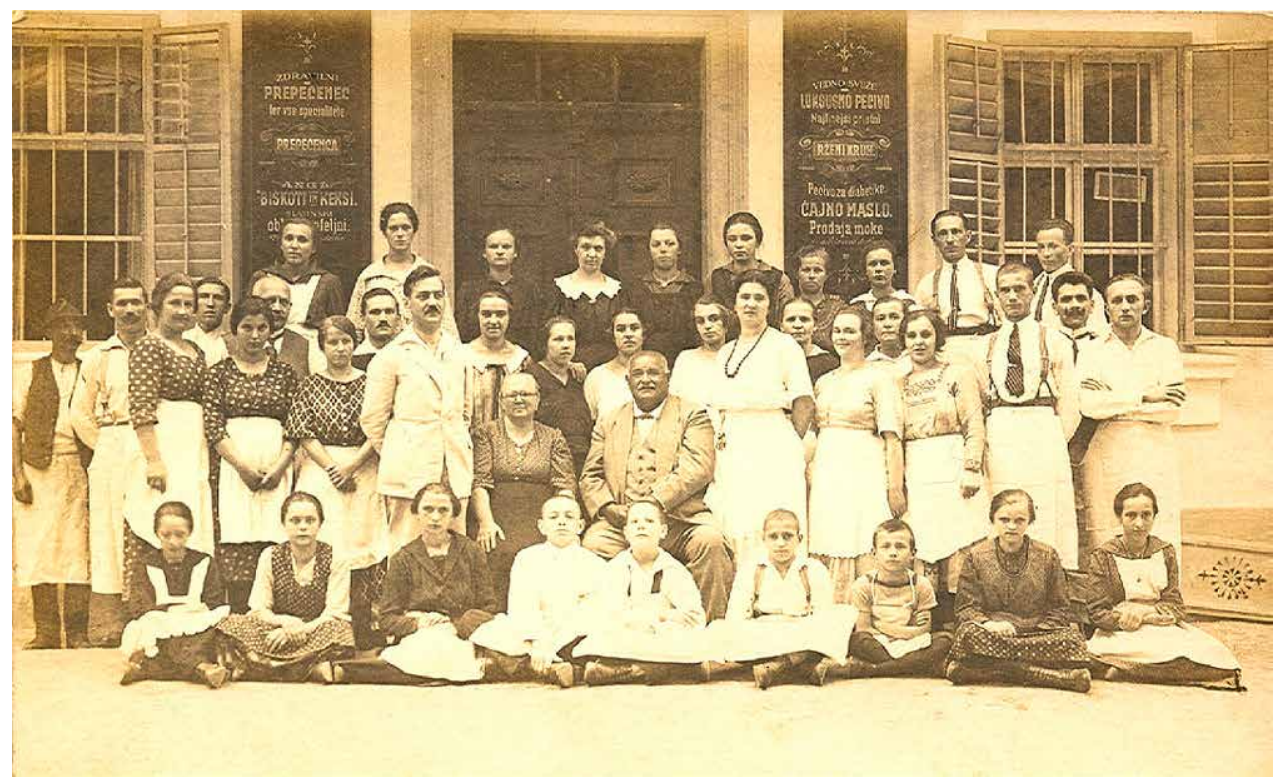

Uslužbenci pred obratom družine Bizjak v Rogaški Slatini (Vir: Knjižnica Rogaška Slatina)

akademski koncepti nanašajo na ureditve in prakse vsakdanjika, na podlagi izhodišča, da moramo danes besedno zvezo "delatilustvarjati kulturo" razumeti hkrati kot "delovati v kulturi« in "delovati s kulturo. (Tschofen 2012: 40)

Za raziskovalce je torej izziv, da se posvetijo tudi vzrokom, zakaj se dediščina uporablja tako, kakor se, in ne se samo, kako se ta uporablja.

\section{REFERENCE}

Bajuk Senčar, Tatiana. 2013. Načrt upravljanja Triglavskega narodnega parka in kultura dediščinskih praks.

Traditiones 42 (2): 9-25. DOI: https://doi.org/10.3986/Traditio2013420201

Baron, Robert in Nick Spitzer. 2010. Public Folklore. Jackson: University Press of Mississippi.

Bausinger, Hermann. 1966. Zur Kritik der Folklorismuskritik. V: Hermann Bausinger, Rudolf Schenda in Herbert Schwedt (ur.), Populus revisus: Beiträge zur Erforschungder Gegenwart. Tübingen: Tübinger Vereinigung für Volkskunde (Volksleben; 14), 61-75. Dostopno na: https://publikationen.uni-tuebingen.de/xmlui/handle/10900/47799

Bendix, Regina. 2009 (1997). In Search of Authenticity: The Formation of Folklore Studies. Madison, WI in London: University of Wisconsin Press.

Bogataj, Janez. 1992. Sto srečanj z dediščino na Slovenskem. Ljubljana: Prešernova družba.

Bošković-Stulli, Maja. 1971. O folklorizmu. Zbornik za narodni život i običaje 45: 165-186. 
Cerar Drašler, Irena. 2004. Pravljične poti Slovenije: Družinski izletniški vodnik. Ljubljana: Sidarta.

Chhabra, Deepak idr. 2003. Staged Authenticity and Heritage Tourism. Annals of Tourism Research 30 (3): 702-719.

Ciglenečki, Jan in Slavko Ciglenečki. 2018. Spiritual Adolf Hytrek in legenda o Gralovem gradu na Boču. Ćasopis za zgodovino in narodopisje 89=54 (1/2): 167-193.

Dégh, Linda. 1994. American Folklore and the Mass Media. Bloomington: Indiana University Press.

Dégh, Linda. 1995. Narratives in Society: A Performer-Centered Study of Narration. Helsinki: Suomalainen tiedeakatemia (FFC; 255).

Demšar, Jožica Amadea. 2017. Skrivnostna gora Boč. Dostopno na: https://tinyurl.com/tqc9qwg

Dorson, Richard M. 1969. Fakelore. Zeitschrift fur Volkskunde 65: 56-64. Dostopno na: https://www. digi-hub.de/viewer/image/DE-11-001938266/70/LOG_0019/

Druškovič, Martin, in Jasna Druškovič. 2014. Izgubljenizaklad: Muzikal. Kostrivnica: Kulturno-prosvetno društvo.

Druškovič, Martin. 2019. Razbojnik Guzej: Muzikal. Kostrivnica: Kulturno-prosvetno društvo.

Fakin Bajec, Jasna. 2011. Procesi ustvarjanja kulturne dediščine: Kraševci med tradicijo in izzivi sodobne družbe. Ljubljana: Založba ZRC, ZRC SAZU (Ethnologica - Dissertationes; 2).

Fikfak, Jurij. 2003. Od tradicije do produkcije lokalnosti - nekatera izhodišča in pogledi. V: Jurij Fikfak (idr., ur.), O pustu, maskah in maskiranju: Razprave in gradiva. Ljubljana: Založba ZRC, ZRC SAZU, 9-20 (Opera ethnologica slovenica).

Gründl, Johann Benedikt. 1687. Roitschocrene, das ist: Aussfübrliche Beschreibung dess in Unter-Steyer weit-berühmbten Roitschen Sauerbrunn : in welcher alle, vnd jede Mineralien, Eigenschafften, vnd Würckungen, nach Galenischer, vnd Chymischer Lehr examinirt, vnd mit Aufflösung viler nothwendigen Fragen entdecket werden, sambt einem nutzlichen Bericht, wie, wann, wie lang, ... diser Brunn ... zugebrauchen, auch wie man sich im Diaet, vnd Kranckheiten Zufällen verhalten soll. Gedruckt zu Grätz: bey denen Widmanstetterischen Erben: zu finden bey Johann Christoph Erhardt.

Habinc, Mateja. 2012. Folklorization as Diversification or Molding: Comparing Two “Traditional” Holidays. Traditiones 41 (1): 185-196.DOI: https://doi.org/10.3986/Traditio2012410116

Hafstein, Tr. Valdimar. 2018. Intangible Heritage as a Festival: or, Folklorization Revisited. Journal of American Folklore 131 (520): 127-149. DOI: https://doi.org/10.5406/jamerfolk.131.520.0127

Hobsbawm, Eric in Terence Ranger (ur.). 2000 (1983). The Invention of Tradition. Cambridge: Cambridge University Press.

Hudales, Jože in Nataša Visočnik (ur.). 2005. Dediščina vočeh znanosti. Ljubljana: Znanstvena založba FF (Županičeva knjižnica; 12).

Ivančič Kutin, Barbara in Monika Kropej Telban. 2018. Ohranjanje nesnovne kulturne dediščine z lokalnimi pripovedmi v prostoru. Traditiones 47 (3): 103-115.DOI: https://doi.org/10.3986/Traditio2018470307

Ivančič Kutin, Barbara in Suzana Marjanić. 2015. »Poslušajte, dragi ljudje, najboljša fabrika je turizem!«: Portret in zgodbe Jožeta Brileja iz Podčetrtka. Glasnik Slovenskega etnološkega društva 55 (3-4): 153-155. Dostopno na: https://www.dlib.si/details/URN:NBN:SI:DOC-USE3R14M

Ivančič Kutin, Barbara. 2013. Pot Po sledeh pripovednega izročila Bovca. V: Podeželski elektronski vodič. Grgarske Ravne: Ustanova Fundacija BiT Planota, 2-3.

Jeranko, Brane. 2009. »Boč je zelo skrivnostna gora«. Novi tednik NTßRC 64 (100): 10.

Jezernik, Božidar (ur.). 2010. Kulturna dediščina in identiteta. Ljubljana: Znanstvena založba FF (Županičeva knjižnica; 31) 
Kamenetsky, Christa. 1977. Folktale and Ideology in the Third Reich. Journal of American Folklore 90 (356): 168-178. DOI: https://doi.org/10.2307/539697

Kirschenblatt-Gimblett, Barbara. 2004. Intangible Heritage as Metacultural Production. Museum International 56 (1-2): 52-65. Dostopno na: https://unesdoc.unesco.org/ark:/48223/pf0000135858

Klaus, Simona. 2012. Folklora v množičnih medijih na Slovenskem v obdobju od 1980 do 2010. Doktorska disertacija. Ljubljana: [S. Klaus].

Klobčar, Marija. 2012. Urbanost kot izziv slovenske etnologije in razmislek folkloristiki. V: Jaka Repič in Jože Hudales (ur.), Antropološki vidiki načinov življenja v mestih. Ljubljana: Znanstvena založba Filozofske fakultete (Zupaničeva knjižnica; 36), 39-58.

Koven, Mikel J. 2003. Folklore Studies and Popular Film and Television: A Necessary Critical Survey.Journal of American Folklore 116 (460): 176-195. Dostopno na: https://www.jstor.org/stable/4137897

Kozorog, Miha. 2014. Etnološki in antropološki pogledi na javne prireditve v Sloveniji. Etnolog 24 (1): 23-41.

Kuret, Niko. 1954. Šaljive zgodbe o Lemberžanih. Maribor: Obzorja.

Leppälahti, Merja. 2011. Meeting Between Species. Traditiones 40 (3): 169-177. DOI: https://doi.org/10.3986/ Traditio2011400312

Makarovič, Marija. 1968. Nekaj misli ob »folklornih prireditvah«:Z opombo uredništva. Glasnik Slovenskega etnološkega društva 9 (2): 3-4.

Mencej, Mirjam. 2007. Po poteh zgodb. Podsreda: Kozjanski park.

Moličnik, Vesna in Špela Pogorelec. 1999. Interaktivno pripovedništvo. Traditiones 28 (1): 437-442.

Moser, Hans. 1962. Vom Folklorismus in unserer Zeit. Zeitschrift für Volkskunde 58: 177-209. Dostopno na: http://www.digi-hub.de/viewer/image/DE-11-001929032/527/

Orožen, Janko. 1936. Gradovi in graščine v narodnem izročilu: 1. Gradovi in graščine ob Savinji, Sotli in Savi. Celje: Samozaložba.

Pažon, Mojca. 2016. Projekt ohranjanja ljudskih. Magistrsko delo. Ljubljana: [M. Pažon]. Dostopno na: http://pefprints.pef.uni-lj.si/4086/1/Mojca_Pa\%C5\%BEon_magistrsko_ delo_DOKON\%C4\%8CNA_OBLIKA.pdf

Poljak Istenič, Saša. 2008. Šege in navade kot folklorizem. Traditiones 37 (2): 61-110. DOI: https://doi. org/10.3986/Traditio2008370204

Poljak Istenič, Saša. 2013.Tradicija v sodobnosti:Janče - zeleni prag Ljubljane. Ljubljana: Založba ZRC, ZRC SAZU (Ethnologica - Dissertationes; 4).

Poljanec, Nani. 2019. Odličen dokument časa. V: Robert Reich, Šniclniza tebe in Slovar slatnskega knjižnega jezika. Rogaška Slatina: Nejamedia, 5-6.

Portis-Winner, Irene. 2005. Semiotika kmetstva v tranziciji: Slovenski vaščani in njihovi sorodniki v Ameriki. Ljubljana: Založba ZRC, ZRC SAZU (Opera ethnologica slovenica).

Reich, Robert. 2019. Šnicl ni za tebe in Slovar slatnskega knjižnega jezika. Rogaška Slatina: Nejamedia.

Slavec Gradišnik, Ingrid. 2000. Etnologija na Slovenskem: Med čermi narodopisja in etnologije. Ljubljana: Založba ZRC, ZRC SAZU.

Slavec Gradišnik, Ingrid. 2010. Slovenian Folk Culture: Between Academic Knowledge and Public Display. Journal of Folklore Research 47 (1-2): 123-151. DOI: https://doi.org/10.2979/JFR.2010.47.1-2.123

Stanonik, Marija, Marko Terseglav in Ingrid Slavec Gradišnik. 2004. Folklorizem. V: Angelos Baš (ur.), Slovenski etnološki leksikon. Ljubljana: Mladinska knjiga, 131-132. 
Stanonik, Marija. 2006. Procesualnost slovstvene folklore: Slovenska nesnovna kulturna dediščina. Ljubljana: Založba ZRC, ZRC SAZU.

Širca, Majda. 2014. Usodne ženske Alfreda Nobela. Delo, spletna izdaja. 6. 12. http://www.delo.si/sobotna/ usodne-zenske-alfreda-nobela.html, 10. 10. 2019.

Šrimpf Vendramin, Katarina. 2015. Ustno izročilo in kulturni spomin v zgornjem Obsotelju. Doktorska disertacija. Nova Gorica: Univerza v Novi Gorici, Fakulteta za podiplomski študij.

Tschofen, Bernhard. 2012. Heritage - Contemporary Uses of Culture Beyond the Everyday? Challenging Ethnography and Cultural Analysis. Traditiones 41 (2): 29-40. DOI: https://doi.org/10.3986/ Traditio2012410202

\section{SPLETNI VIRI}

Spletni vir 1: Živa coprnija Pohorja in Istre. http://zivacoprnija.com/

Spletni vir 2: Občinski simboli. http://www.rogaska-slatina.si/txt/1/80/grb-zastava-in-praznikobcine-rogaska-slatina

Spletni vir 3: Steklarna Rogaška. https://steklarna-rogaska.si/o-nas/

Spletni vir 4: Boč in njegova (po)moč. http://amadeajd.weebly.com/bo269-in-njegova-pomo269.html.

Spletni vir 5: Terra parzival. http://www.terraparzival.net/the-call-of-grail-terra-parzival-awakening/

Spletni vir 6: Predlog regijskega projekta za vključitev v RRP 2014-2020 - Regija Podravje; Terra Parzival. http://terraparzival.net/files/slike/SRR_Obrazec_Terra_Parzival_Evropski_Model_regionalnega_razvoja_dopolnitve_jan_2014.pdf

\section{CONTEMPORARY USE OF NARRATIVE HERITAGE IN THE MUNICIPALITY OF ROGAŠKA SLATINA AND ITS SURROUNDINGS}

Elements of cultural heritage are used for political and ideological purposes, for culture and tourist events, or as a field for inspirations by various artists - from folkdance groups to playwrights and other artists. The occurrence of various forms of heritage are constantly discussed in research articles. Here the author presents and analyses various practices of heritage use in the Municipality of Rogaska Slatina and the surrounding area. It focuses on the functions and aspects offolklorism in the local environment.

As early as the first half of the twentieth century, folklorists began to notice the economic commodification and political manipulation of elements of intangible cultural heritage. They initially labeled these phenomena folklorism: something that is not true folklore, but "secondary folk" or "secondhand folklore." Today, the term folklorism is mostly understood simply as an adaptation, or a transformation of heritage. 
Exploiting various forms of heritage for commercial purposes is not a new practice. One of the market's tourist approaches is various theme trails and parks based on fairytales and local storytelling, which have become quite a popular tourist product in recent years. There are many such routes in Slovenia, including near Rogaška Slatina.

The contemporary phenomena of folklorism can also be understood to include the usage of various forms of heritage, which by their appearance represent the symbolic identity of the local community or beyond. Thus, the local narrative tradition has found its way onto the stage in Rogaska Slatina. Narratives that are part of oral tradition were taken as a basis by the creators of the performances, and they have developed and transformed them into musicals, songs, and stage performances.

Among the all forms of folklorism in the research area, the most interesting case is the story and image of Pegasus, a symbol of the Municipality of Rogaška Slatina. Due to its recent date of construction, we can follow the processes of creation and identification with this symbol, and thus the emphasis and constant production of the local affiliation with this image. Namely, over the years Pegasus has become a symbol that the inhabitants of the municipality also use to identify themselves emotionally, and the municipality's coat of arms and flag show its independence and identity, which is built on legitimization of the historicity of the place.

An example offolklorization that rebuilds the connection between Mount Boč and surrounding places are stories and events relating to the medieval epic Parzival. Cultural events based on these place Mount Boc and surrounding sites in a mythological landscape. According to the findings of a field study, only a handful of people know the story, which in a way also indicates the deliberate "awakening" of some stories - or rather, inventing new ones that represent Boc as a sacred space and connect it with the castle of the Holy Grail.

Heritage often has an emotional charge in folklorism phenomena, and there is frequently also a romantic relationship to it in the sense that it is necessary to protect it or display it because it is disappearing. However, when local heritage is strongly emphasized in the form offolklorism, it offers the possibility of local identification, which can be very strong, as seen in the case of Rogaška Slatina.

Dr. Katarina Šrimpf Vendramin, asistenka ZRC SAZU, Inštitut za slovensko narodopisje Novi trg 2, SI-1000 Ljubljana, katarina.srimpf@zrc-sazu.si 